\title{
SARS-CoV-2 / COVID-19: Salient Facts and Strategies to Combat Ongoing Pandemic
}

\author{
Ranjit Sah $^{1 *}$ (D) Nayanum Pokhrel ${ }^{2}$ (D) Zareena Fathah $^{3}\left(\mathbb{D}\right.$, Akihiko Ozaki $^{4,5}$ (D), \\ Divya Bhandari ${ }^{5}\left(\mathbb{D}\right.$, Yasuhiro Kotera ${ }^{6}$ id , Niranjan Prasad Shah ${ }^{1}(\mathbb{D}$, Shailendra \\ Sigdel $^{7}\left(\mathbb{D}\right.$, Kranti Suresh Vora ${ }^{8,9}(\mathbb{D})$, Senthil Kumar Natesan ${ }^{8}(\mathbb{D})$, Shailesh Kumar \\ Patel $^{10}\left(\mathbb{D}\right.$, Ruchi Tiwari ${ }^{11}$ (D) Yashpal Singh Malik ${ }^{12}$ (D) Mohd. Iqbal Yatoo ${ }^{13}$, \\ Alfonso J Rodriguez-Morales ${ }^{14,15}$ (D) and Kuldeep Dhama ${ }^{10 *}$ (iD
}

${ }^{1}$ Tribhuvan University Teaching Hospital, Institute of Medicine, Kathmandu, Nepal. ${ }^{2}$ Kanti Children's Hospital, Kathmandu, Nepal. ${ }^{3}$ Royal Holloway, University of London, London, UK. ${ }^{4}$ Department of Breast Surgery, Jyoban Hospital of Tokiwa Foundation, Iwaki, Japan. ${ }^{5}$ Medical Governance Research Institute, Minato-ku, Tokyo Japan. ${ }^{6}$ University of Derby, Derby, UK. ${ }^{7}$ Department of Cardiothoracic and Vascular Anesthesiology, Manmohan Cardiothoracic Vascular and Transplant Center, Maharajgunj Medical Campus, Institute of Medicine, Tribhuvan University, Kathmandu, Nepal. ${ }^{8}$ Indian Institute of Public Health Gandhinagar, Lekawada, Gandhinagar - 382 042, Gujarat, India. ${ }^{9}$ Institute of Health Research, University of Canberra, ACT 2617, Australia. ${ }^{10}$ Division of Pathology, ICAR-Indian Veterinary Research Institute, Izatnagar - 243 122, Bareilly, Uttar Pradesh, India. ${ }^{11}$ Department of Veterinary Microbiology and Immunology, College of Veterinary Sciences, UP Pandit Deen Dayal Upadhayay Pashu Chikitsa Vigyan Vishwavidyalay Evum Go-Anusandhan Sansthan (DUVASU), Mathura - 281 001, Uttar Pradesh, India. ${ }^{12}$ Division of Biological Standardization, ICAR-Indian Veterinary Research Institute, Izatnagar, Bareilly - 243 122, Uttar Pradesh, India. ${ }^{13}$ Division of Veterinary Clinical Complex, Faculty of Veterinary Sciences and Animal Husbandry, Shuhama, Alusteng Srinagar, Sher-E-Kashmir University of Agricultural Sciences and Technology of Kashmir, Shalimar, Srinagar - 190 006, Jammu and Kashmir, India. ${ }^{14}$ Public Health and Infection Research Group, Faculty of Health Sciences, Universidad Tecnologica de Pereira, Pereira, Colombia. ${ }^{15}$ Grupo de Investigacion Biomedicina, Faculty of Medicine, Fundacion Universitaria Autonoma de las Americas, Pereira, Risaralda, Colombia.

*Correspondence: ranjitsah57@gmail.com; kdhama@rediffmail.com

(Received: July 24, 2020; accepted: August 17, 2020)

Citation: Sah R, Pokhrel N, Fathah Z, et al. SARS-CoV-2 / COVID-19: Salient Facts and Strategies to Combat Ongoing Pandemic. J Pure Appl Microbiol. 2020;14(3):1663-1674. doi: 10.22207/JPAM.14.3.04

(C) The Author(s) 2020. Open Access. This article is distributed under the terms of the Creative Commons Attribution 4.0 International License which permits unrestricted use, sharing, distribution, and reproduction in any medium, provided you give appropriate credit to the original author(s) and the source, provide a link to the Creative Commons license, and indicate if changes were made. 


\begin{abstract}
Severe acute respiratory syndrome coronavirus - 2 (SARS-CoV-2), an emerging novel coronavirus causing coronavirus disease 2019 (COVID-19) pandemic, has now rapidly spread to more than 215 countries and has killed nearly $\mathbf{0 . 7 5}$ million people out of more than $\mathbf{2 0}$ million confirmed cases as of $10^{\text {th }}$ August, 2020. Apart from affecting respiratory system, the virus has shown multiple manifestations with neurological affections and damaging kidneys. SARS-CoV-2 transmission mainly occurs through close contact of COVID-19 affected person, however air-borne route is also now considered as dominant route of virus spread. The virus has been implicated to have originated from animals. Apart from bats, pangolins and others being investigates to play role in transmitting SARS-CoV-2 as intermediate hosts, the recent reports of this virus infection in other animals (cats, dogs, tigers, lions, mink) suggest one health approach implementation along with adopting appropriate mitigation strategies. Researchers are pacing to develop effective vaccines and drugs, few reached to clinical trials also, however these may take time to reach the mass population, and so till then adopting appropriate prevention and control is the best option to avoid SARS-CoV-2 infection. This article presents an overview on this pandemic virus and the disease it causes, with few recent concepts and advances.
\end{abstract}

Keywords: SARS-CoV-2, COVID-19, pandemic, prevention, control

\section{INTRODUCTION}

In December 2019, the wet market in the city of Wuhan, China saw the beginning of a deadly outbreak with an unexpected new strain of beta-coronavirus, severe acute respiratory syndrome coronavirus - 2 (SARS-CoV-2), causing coronavirus disease 2019 (COVID-19). Beginning as an outbreak within China, this virus rapidly spread across many nations and continents making it a pandemic that is now posing the worst situation after the 1918 Spanish flu virus pandemic which killed millions of people. Presently, SARS-CoV-2 has very quickly affected more than 215 countries while accounting for nearly 0.75 million deaths out of more than 20 million positive cases as of 10th August, 2020. In addition to a very severe global health concerns it also led to very high social and economic instability and huge panic and fear to the public ${ }^{1,2}$. In order to attempt to stop it from rapidly spreading, many countries followed locked down, halted their social and business activities, causing significant damages to their economy, GDP and share markets ${ }^{3-6}$.

Among previously known coronaviruses, this strain was unique in its nature since it had not been previously identified in humans. Preliminary research indicates bat as the primary reservoir of virus suggesting close similarity of SARS-CoV-2 to bat coronavirus ${ }^{7}$. This virus is said to mutate twice a month and is easily transmitted through respiratory secretions of an infected person to a susceptible person in close contact approximately within 6 feet or more ${ }^{8}$. Air-borne transmission has also been reported to be a dominant route of transmission. Although factors such as humidity and temperature have shown to affect the survival of the pathogen, numerous studies have claimed the infectious nature of the virus on inanimate objects and surfaces at room temperature for up to 9 days $^{9}$. The abundance of the susceptible host is a promising factor deciding the invasion and spread of a new pathogen. This susceptibility is difficult to explain because of prior cross-protective immunity in population recently exposed to similar antigenic pathogens. Epidemiological information of the co-circulating viruses provides an understanding of the immune potential, virus-virus interactions and population susceptibility ${ }^{10}$. No particular antiviral treatments and vaccines are available for COVID-19, and this endeavors to create antivirals and vaccines at an early time to counter ongoing pandemic. The present article highlights main features SARS-CoV-2 / COVID-19 and recent advances to counter it.

\section{Transmission and Spread}

Coronaviruses (CoVs) including SARSCoV-2 spread mainly via respiratory droplets released from the mucus secretions and saliva 
from the nose and mouth during the act of sneezing, coughing, talking, laughing, singing and breathing. These droplets containing the virus may gain access to the body mainly through the eyes, nose and mouth but not through intact skin. Droplets fall on the ground or settle on the surfaces if they do not hit any inanimate object, while on their trajectory to settling down; thereby serving as a mode of self-inoculation among healthy individuals. In addition, CoVs may remain infective on metal, glass and plastic surfaces for a period of 2 hours to 9 days. In contrast to this, SARS-CoV-2 may persist in air from 3 hours to an average of 2-3 days in steel and plastic surfaces ${ }^{11}$. Application of a simple disinfectant including soap and diluted solution of sodium hypochlorite or a diluted household bleach over contaminated surfaces may consider them safe as the delicate envelope of the virus gets easily destroyed by disinfectants. Although CoVs are not transmitted sexually but kissing could definitely transmit the disease. In addition, SARSCoV-2 has been reported in feces, although its significant role in feco-oral transmission has not been determined ${ }^{12}$. Therefore, the role of hand sanitization after using toilet plays a pivotal role in preventing the spread of the COVID-19 after the evidence of passage of virus in feces and urine.

For an infection to occur, patients found positive with SARS-CoV-2 must be in close contact (within 6 feet) with a susceptible host for at least 15 minutes or should be in a closed environment, where an infected patient has the ability to spread the virus in an area with a pre-existing low viral load in air $^{13}$. For e.g., in a case scenario, the chances of a taxi driver getting infected with the pathogen while carrying a diseased passenger to a 5 minute airport ride is less. In contrast, if a health care personnel examining a suspected case of COVID-19, showing typical features of acute respiratory illness, coughing for more than 15 minutes, without taking any protective measures or maintaining adequate respiratory etiquette is more likely to get infected with the virus. Meanwhile another health care professional entering the same room where the suspected case is being examined can get infected easily due to the presence of pre-existing viral particles present in the air.

\section{COVID-19: Clinicopathology}

SARS-CoV-2 is closely related to SARS virus with respect to sharing of the same receptor viz. ACE-2 receptor for entry into the host cells. In contrast to previous two coronavirus epidemics with SARS and MERS, the SARS-CoV-2 is found less lethal but highly contagious. Death related to COVID-19 is mainly attributed to respiratory failure because of cytokine storm due to overstimulation of immune system ${ }^{14}$. The clinical symptoms manifested by SARS-CoV-2 patients depend upon the disease severity and immune status of the individuals. Moreover, on the basis of clinical symptoms the COVID-19 is stratified into critical/ severe, moderate, mild and asymptomatic forms ${ }^{15}$. Among all the forms, the severe form is particularly observed in elderly and immune-compromised persons with known comorbidities ${ }^{16,17}$. COVID-19 incubation period is variable, mean value of 5.2 days has been observed, and mainly depends on disease severity ${ }^{16,18}$. The clinical symptoms include fever, muscle ache, generalized weakness, dyspnoea, rhinorrhea, dry cough, pleuritic chest pain, dry and less commonly hemoptysis, headache, diarrhoea, nausea and vomiting ${ }^{15,19-23}$. Moreover, fever and cough are the most common clinical signs of COVID-19.24 The current evidence suggests multiple organ systems may be affected by hyperinflammation in SARS-CoV- 2 infection ${ }^{25}$. In this context, neurodegeneration, neuroinflammation, and delirium in some COVID-19 cases might be attributed to inflammatory response in central nervous system (CNS) ${ }^{26}$. In addition, neurological manifestations such as anosmia and ageusia have been observed as salient symptoms during SARSCoV-2 infection ${ }^{27}$.

The virus has also been reported to cause neurological manifestations as well as affect other organs including kidneys. Pregnancy related immune-suppression is found to be beneficial as far as severity of the disease is concerned. The presence of viral RNA in all body fluids, respiratory secretions and feces of infected individuals has been described in scientific literatures. Young children are also affected with the SARS COV-2 and most of them recover without any major disease associated events. It has been observed that some young children diagnosed with COVID-19 had classic Kawasaki disease (KD) or a KD-like disease, 
that may be a significant clinical manifestation of pediatric COVID-1928. Vertical transmission from infected mother to neonates as per the studies suggest the implementation of robust neonatal healthcare monitoring systems ${ }^{29}$.

Liang et al. (2020) showed COVID-19 mortality rate to be negatively related to the test numbers ${ }^{30}$. The higher mortality is related to lower test number, ageing population, fewer hospital or beds and better infrastructure. However, the test number and population screening for reducing mortality are under debate. Few studies also reported the old age and different comorbidities for higher mortality ${ }^{21,31}$.

\section{Biosafety measures, Quarantine and Isolation}

Since, the physical social distance to be maintained from a patient is uncertain, the prevention or treatment option relies on nonpharmaceutical approaches, pandemic mitigation strategies until an effective treatment or vaccine becomes available ${ }^{32}$. Maintaining hand hygiene by regular hand washing plays an important role in breaking chain of transmission. The use of surgical mask is not recommended as it won't prevent the small airborne particles from inhalation. The surgical mask can only filter pathogens above 2 microns. However, this virus is 0.12 microns in size, thereby raising the possibility of viral transmission mainly from hand to the mucous membrane of the aforementioned sites while frequently trying to adjust the mask. A more specialized mask, known as an $\mathrm{N} 95$ respirator, is thicker than a surgical mask, which filters almost 95 percent particles of 0.0001 inches ( 0.3 microns) in diameter ${ }^{33,34}$. This mask is to be worn specifically by patients and health care professionals handling infected patient, their samples, waste and surroundings ${ }^{35}$. However the likelihood of prevention of infection by wearing such respirators has not yet been proved.

Since SARS-CoV-2 incubation period is usually 2-14 days ${ }^{36}$, therefore those who need to be quarantined, should be quarantined for 14 days in an open well-ventilated area. Quarantine in a semi-closed environment (e.g. ships and hotels) may be counter-productive ${ }^{37}$. In a semiclosed environment, the virus incubates easily and spreads quickly between individuals, leading to widespread transmission as seen in Diamond Princess, a quarantined cruise ship in Japan.
Similar to the inevitable rampant spread of the virus in Diamond Princess Cruise ship, another outbreak occurred in Grand Princess, a voyage ship which was on a 15-day trip from San Francisco to Hawaii. Grand princess tour witnessed the unfortunate outbreak and had difficulty on tracing the source of infection, which eventually found a 71 year old man from California harboring the virus. Prior to sail, he had visited Mexico for a brief period of time from Feb $11^{\text {th }}-21^{\text {st }} 2020$. He died of the COVID-19 infection during his voyage $^{38}$. Out of 3,533 people in the trip, only 46 were tested. Amongst them 21 were found to be infected with COVID-19 with 19 of them being staff members. The Cruise has been circling along the coast of California for several days until $9^{\text {th }}$ March 2020, when they finally docked in Oakland. Four different Military bases in California, Texas, and Georgia were prepared for quarantine of passengers on sail. Nearly, 1000 passengers residing in California were taken either to Travis Air Force Base, near Fairfield, or Marine Corps Air Station Miramar, near San Diego and remaining to federal facilities out of states ${ }^{39}$.

Standard quarantine practices recommend a minimum of two weeks period quarantine before discharging patients, as the pattern of viral shedding of COVID-19 is still unclear.18 Strict quarantine measures of all known and possible interactions with the infected individual are to be traced. Social distancing along with community quarantine plays a pivotal role in curving the infection and may prove vital in ongoing pandemic. 40

Standard quarantine practice includes a combination of movement restriction along with clinical care of individuals exposed to close contacts with patients in addition to rapid, comprehensive contact tracing of all confirmed cases. Quarantined individuals must record their temperature followed by assistance of a healthcare team daily. In case of development of the symptoms meeting the case definition of COVID-19, the individual must be investigated and referred to designated hospital. In addition, if a disease develops under quarantine period, it would not spread further, resulting in lowering of reproduction number $\left(R_{0}\right)$ to less than 1 . Once contact tracing of infected individuals is 
not possible, community-wide containment is then applied to reduce personal contacts like suspension of public gatherings, social distancing and community quarantine ${ }^{41}$.

To avoid air-borne route of SARS-CoV-2 transmission, social distancing of 6 feet / 2 meters or more from an infected person along with following personal biosafety measures including wearing face masks and hand washings are required ${ }^{42-44}$. Small particles loaded with virus may diffuse of up to $10 \mathrm{~m}$ distance from source of infection, which is of high concerns in spreading this virus dominantly by air-borne route ${ }^{45}$. SARS-CoV-2 RNA was also detected in sewage and wastewater, hence water-borne route of transmission need to be checked and investigated by wastewaterbased epidemiology, sewage surveillance along with emphasis on fecal-oral transmissions, which would aid in prevention and control strategies to check spread of this pandemic virus ${ }^{46-50}$. There was no significant relation between temperature, humidity, and the virus distribution ${ }^{51}$.

Why elderly people have more mortality rate than children and adult?

Elder people generally over 60 years of age are at larger risk of COVID-19, with increased mortality in individuals above the age of 80 years. Likely explanation to this observation may be due to the presence of other chronic diseases like high blood pressure, diabetes, kidney disease, cancer, frail immune conditions and overall poor health increasing the mortality among the elderly $^{52}$. In contrast; stronger immune system with fewer/no co-morbid conditions, likely exposure to other coronaviruses may reduce the predisposition to infection as in children and younger people ${ }^{53}$. Researches showed that men were more affected than women due to increased travel patterns exposing them to asymptomatic or pre-symptomatic carriers. So far there are no proven inherent biological differences among the two genders ${ }^{52}$.

Pregnancy and birth outcomes in COVID 19

Maternal viral infections can adversely affect pregnancy outcome and preliminary research being done in developed countries hinted towards COVID-19 association with increased events of miscarriage, preterm birth and respiratory distress during pregnancy. Previous studies have shown high rates of spontaneous abortion and preterm birth among mothers infected with SARS during pregnancy. Although no evidence is there that foetal growth retardation (FGR) occurs due to COVID-19, two-thirds of pregnancies with SARS showed FGR, so ultrasound need to be carried out. Impact of the infection on infants born to infected mothers has not been looked into and for a country like India where such data is scarce it is important to understand long term impacts on the children. Currently, the effect of COVID19 on pregnancy outcome in developing nations is unclear.

Clinically, SARS-CoV-2 infection characteristically induces cytokine storm, with elevated plasma levels of inflammatory cytokines such as MIP- $1 \alpha$, TNF-A etc. In the context of pregnancy, maternal inflammation is known to affect fetal brain development leading to various behavioural disorders later in life. For example, increased maternal inflammatory cytokine IL-17a is known to induce autism spectrum like disorder in children. Cytokine storm and hyper-inflammation in pregnant women having SARS-CoV infection can elevate risks for neurodevelopmental disorders in the newborns ${ }^{54}$. Malaria induced increased inflammatory cytokines such as TNF-A, IFN-G in maternal circulation is correlated with poor birth outcome. Therefore, there is a need to evaluate the load of pro-inflammatory cytokines among SARSCoV-2 infected pregnant women and their correlation with birth outcome.

A probable passage of virus from the SARS-CoV-2 infected pregnant mother to the amniotic fluid has not been evidenced as well as vertical transmission of SARS-CoV-2 has also not been evidenced during late stages of pregnancy and vaginal delivery ${ }^{55,56}$.

COVID-19 pandemic has elevated anxiety levels and few mental health illnesses in pregnant women as pregnancy period has delicate uncertainties. Lockdown along with financial issues can add to the anxiety. There is also a higher risk of domestic abuse during pregnancy, which has skyrocketed in this ongoing COVID-19 pandemic ${ }^{57}$. Treatment regimen of COVID-19 in pregnancy also has to be looked at carefully. Although clinical studies on chloroquine and hydroxy-chloroquine in pregnant women are assuring when used against 
malaria, however these drugs are genotoxic ${ }^{58}$. There is a need to have studies of their impact during COVID-19 treatment.

Why is there a variation in transmission rate amongst countries with many showing a widespread increase in cases while some such as Turkmenistan, Bhutan, and Burundi etc. are reporting their first few cases or no cases?

Countries like Turkmenistan and Democratic People's Republic of Korea have no confirmed cases till July 26, 2020, whereas countries like Bhutan, Falkland Islands (Malvinas) and Papua New Guinea have less than 100 cases. Few of the individuals were suspected due to travel history from COVID-19 affected areas with mild symptoms but were all tested negative. Some countries have initiated strict social distancing measures mandating individuals on a 14-day self-quarantine practices among their fellow citizens returning from abroad ${ }^{59}$. The government of Singapore cancelled all public events and installed medical booths to measure the core body temperature to screen and detect cases at their earliest for isolation and clinical management. Papua New Guinea has imposed travel restrictions to affected areas as well as prevented cruise ships and tourists from entering their nation. Italy's preparedness to tackle COVID-19 pandemic included shutting down educational institutions, executing travel restrictions and prohibition to mass gatherings.

Animal linkages and cross-species jumping

The virus is reported to have emerged from bats but the search for an intermediate host still remains obscure. Reptiles and endangered animals such as snakes, pangolins, and other mammals are suspected to be the intermediate host, however in-depth studies are required to reach to any conclusion. SARS-CoV-2 has been documented to be of animal origin, jump the crossspecies barrier and possess zoonotic concerns ${ }^{60}$. SARS-CoV-2 infection has been identified in pet, farmed and zoo animals (cats, dogs, tigers, lions and minks), while ferrets and primates also reported to be susceptible ${ }^{61-65}$. The concept of reverse zoonosis has been stated in studies where a dog was found to be infected from its owner. Surveillance and monitoring of SARS-CoV- 2 in animals must be undertaken via rapid detection, using geographical information system (GIS) and tracking tools along with implementing one health approach and other necessary mitigation measures ${ }^{61,66-68}$.

Developing vaccines, drugs and a global cure to fight COVID-19 pandemic

Researchers across the world are making very high efforts to develop vaccines, prophylactics, drugs/medicines and therapies to combat COVID-19, halt SARS-CoV-2 spread and safeguard health of mass population, few of which have reached clinical trials but may take time of few more months to reach to the market ${ }^{69-74}$ Vaccine candidates being explored include mRNA vaccine, DNA vaccine, vectored vaccine, virus like particles (VLPS) vaccine along with attempts for developing inactivated and attenuated SARSCoV-2 vaccines. Antiviral drugs like remdesivir, favipiravir, umifenovir, oseltamivir, lopinavir/ ritonavir and anti-malarial drugs chloroquine and hydroxychloroquine have shown fruitful results in treating COVID-19 patients. The modern upcoming tools of artificial intelligence (AI) and CRISPR are also being utilized to design effective vaccines and therapeutics against SARS-CoV- $2^{75,76}$. The fields of bioinformatics, cheminformatics, structure-based drug development, network-based techniques predicting drug-target interactions, $\mathrm{Al}$ and machine learning could aid for designing anti-SARS-CoV-2 drugs $^{77}$. Apart from developing vaccines and antiviral drugs, few of the potent therapeutics showing promising results in treating COVID-19 patients comprise of neutralizing antibodies, monoclonal antibodies, intravenous immunoglobulin (IVIg), natural killer (NK) cell based immunotherapies, convalescent plasma therapy and different kind of immunomodulatory agents ${ }^{78-82}$. Dietary intake of balanced and nutritious foods along with supplementation of nutraceuticals, probiotics, plant-based molecules / phytochemicals, herbs and traditional medicines, Ayurvedic products, zinc and vitamins ( $A, C, E, B 6$ and $B 12)$ have been suggested to regulate and enhance immunity of the body to fight against SARS-CoV-2 infection developing into disease (COVID-19), as were found effective against other viral diseases ${ }^{83,84,92,85-89,89-91}$. Besides, doing daily exercises and yoga activities also help in maintaining the biological function and boost immunity to safeguard from this pandemic 
virus. In the current situation where no effective vaccine or drug is still available, boosting of the immune system with a holistic approach following different regimens as discussed, having synergistic effects, could protect, provide probable cure and would aid in flattening of the COVID-19 rising pandemic curves ${ }^{93-97}$.

The targeted repurposing strategies provide a fast method for approved treatment. Large scale screening of known drugs can provide a better pre-clinical and clinical evaluation. A highthroughput reprofiling screen using the ReFRAME (Repurposing, Focused Rescue, and Accelerated Medchem) provide access to a large number of drugs in clinical or pre-clinical trials and help in characterizing drugs for SARS-CoV- $2^{98}$.

The COVID-19 outbreak could judge preparation of countries for major medical health emergencies. It also provides an opportunity to develop and safeguard world with preparations to counter future health emergencies and pandemics. Increasing the test number and better infrastructure facility can reduce mortality. Also, the estimation of physical distancing will help in developing guidelines for control of COVID-19. To assess the health care burden of COVID-19 on population, continuous monitoring of co-circulating viruses is required for developing guidelines and research priorities in the susceptible population. Further studies are required to know the modes of interactions between CoVs and severity of COVID-19.

\section{CONCLUSION AND FUTURE PROSPECTS}

In spite of strengthening of healthcare system with increased testing, contact tracing, and implementation of strict control measures such as lock down, travel restrictions, masks, and social distancing, the virus found its way to spread rapidly among the people in different countries when such measures are relaxed or removed. The economic activities are severely affected in many countries and it is on the verge of collapse in many countries affecting the livelihood of millions of people in several low- and middle-income countries. Such measures could not be implemented for prolonged time as the economic activities need to be reviewed with extreme precautions. While doing so, we need to protect the highly vulnerable elderly population who are severely affected by this virus and the young people should be allowed to resume their work with precautionary preventive measures. As this virus spreads through aeroso ${ }^{99}$, wearing masks, maintaining social distance, following hand hygiene, avoiding any gatherings, avoid meetings in closed rooms with poor ventilation, avoid serving food or drink during the office meetings, etc need to be strictly followed to stop the chain of transmission ${ }^{100}$. Though the virus is detected in stool samples, fecal-oral route of transmission may not play an important role ${ }^{29,101}$. However, it may play significant role while people use common toilets in public places.

People with any sign of sickness should self-isolate and stay at home. A false sense of complete protection from virus while wearing masks need to be discouraged as mask can only reduce the risk of acquiring an infection and it does not provide complete protection against virus. It is becoming clear now that the virus is not going to disappear anytime soon. During the initial phase of the pandemic, it was perceived that an effective control measure such as lockdown can prevent the virus spread. Though it worked till the lockdown was strictly implemented. However, when the lockdown was removed and people activities have started, a massive increase in the cases were observed in several countries. It appears that the virus will be circulating in human population for prolonged period of time.

A successful vaccine could change the natural course of this disease. Until then, people need to learn to live with this virus following strict preventive measures as mentioned above. A behavioral change is much needed to improve the personal hygiene and mask hygiene. A dirty and reused mask is more dangerous than not wearing mask. Thus, everyone needs to ensure the mask it clean and it should be washed or disinfected and used appropriately.

The control of COVID-19 pandemic appears to be more complicated than previously thought. The spread of SARS-CoV-2 from asymptomatic persons, persistence of virus in contaminated surfaces, air-borne transmission, variation among susceptibility of people to viral infection, severity of disease and rapidly 
increasing pandemic waives and highly rising cases continuously have altogether also made several limitations and lacunae in the prevention and control strategies ${ }^{51,102}$. The natural course of reduced virulence of the virus, our improved ability to manage the patients with better health systems, availability of specific treatments and vaccine can significantly boost our ability to control ongoing COVID-19 pandemic. Some of these factors are already contributing to the reduced case fatality rate worldwide.

\section{ACKNOWLEDGMENTS}

All the listed author(s) are thankful to their representative universities/institutes for providing the related support to compile this work.

\section{CONFLICT OF INTEREST}

The authors declare that there is no conflict of interest.

\section{AUTHORS' CONTRIBUTION}

All the listed author(s) have made a substantial, direct, and intellectual contribution to the work, and approved it for publication.

\section{FUNDING}

None.

\section{ETHICS STATEMENT}

This article does not contain any studies with human participants or animals performed by any of the authors.

\section{DATA AVAILABILITY}

Not applicable.

\section{REFERENCES}

1. Zhu N, Zhang D, Wang W, et al. A novel coronavirus from patients with pneumonia in China, 2019. N Engl J Med. 2020;382(8):727-733. doi: 10.1056/ NEJMoa2001017

2. Hayat R, Groot E de, Erken H, Vogel S. Economic implications of the coronavirus - RaboResearch. https://economics.rabobank.com/publications/2020/ january/economic-implications-of-the-coronavirus/\#. Accessed July 26, 2020.

3. Ahmad T, Haroon, Dhama K, et al. Biosafety and biosecurity approaches to restrain/contain and counter SARS-CoV-2/ COVID-19 pandemic: A rapidreview. Turkish J Biol. 2020;44(Special issue 1):132145. doi: 10.3906/biy-2005-63
4. Ayittey FK, Ayittey MK, Chiwero NB, Kamasah JS, Dzuvor C. Economic impacts of Wuhan 2019-nCoV on China and the world. J Med Virol. 2020;92(5):473-475. doi: 10.1002/jmv. 25706

5. Keni R, Alexander A, Nayak PG, Mudgal J, Nandakumar K. COVID-19: Emergence, Spread, Possible Treatments, and Global Burden. Front Public Heal. 2020;8:216. doi: 10.3389/fpubh.2020.00216

6. Nicola M, Alsafi Z, Sohrabi C, et al. The socio-economic implications of the coronavirus pandemic (COVID-19): A review. Int J Surg. 2020;78:185-193. doi: 10.1016/j. ijsu.2020.04.018

7. Kandel N, Chungong S, Omaar A, Xing J. Health security capacities in the context of COVID-19 outbreak: an analysis of International Health Regulations annual report data from 182 countries. Lancet. 2020;395(10229):1047-1053. doi: 10.1016/S01406736(20)30553-5

8. Center for Disease Control and Prevention (CDC ). How Coronavirus Spreads . https:// www.cdc.gov/coronavirus/2019-ncov/ prevent-getting-sick/how-covid-spreads. html?CDC_AA_refVal=https\%3A\%2F\%2Fwww. cd c. gov\% 2 F coronavirus\% 2 F 2019 ncov\%2Fprepare\%2Ftransmission.html. Accessed July 26, 2020.

9. Kampf G, Todt D, Pfaender S, Steinmann E. Persistence of coronaviruses on inanimate surfaces and their inactivation with biocidal agents. J Hosp Infect. 2020;104(3):246-251. doi: 10.1016/j.jhin.2020.01.022

10. Nickbakhsh S, Ho A, P Marques DF, McMenamin J, Gunson RN, Murcia PR. Epidemiology of Seasonal Coronaviruses: Establishing the Context for the Emergence of Coronavirus Disease 2019. J Infect Dis. 2020. doi: $10.1093 /$ infdis/jiaa185

11. Bedford T. Cryptic transmission of novel coronavirus revealed by genomic epidemiology. bedford lab. 2020. https://bedford.io/blog/ncov-cryptic-transmission/. Accessed July 26, 2020.

12. Coronavirus: The Case for Canceling Everything - The Atlantic. https://www.theatlantic.com/ ideas/archive/2020/03/coronavirus-canceleverything/607675/. Accessed July 26, 2020.

13. Papineni RS, Rosenthal FS. The size distribution of droplets in the exhaled breath of healthy human subjects. J Aerosol Med Depos Clear Eff Lung. 1997;10(2):105-116. doi: 10.1089/jam.1997.10.105

14. Mehta P, McAuley DF, Brown M, Sanchez E, Tattersall RS, Manson JJ. COVID-19: consider cytokine storm syndromes and immunosuppression. Lancet. 2020;395(10229):1033-1034. doi: 10.1016/S01406736(20)30628-0

15. Dhama K, Kumar Patel S, Pathak M, et al. Review An Update on SARS-COV-2/COVID-19 with particular reference on its clinical pathology, pathogenesis, immunopathology and mitigation strategies-A Review. 2020. doi: 10.20944/preprints202003.0348.v1

16. Huang $\mathrm{C}$, Wang $\mathrm{Y}, \mathrm{Li} X$, et al. Clinical features of patients infected with 2019 novel coronavirus in Wuhan, China. The Lancet. 2020;395:497. doi: 10.1016/S01406736(20)30183-5

17. Wang W, Tang J, Wei F. Updated understanding of the 
outbreak of 2019 novel coronavirus (2019-nCoV) in Wuhan, China. J Med Virol. 2020;92(4):441-447. doi: 10.1002/jmv.25689

18. Li Q, Guan X, Wu P, et al. Early Transmission Dynamics in Wuhan, China, of Novel Coronavirus-Infected Pneumonia. N Engl J Med. 2020;382(13):1199-1207. doi: 10.1056/NEJMoa2001316

19. Chan JFW, Kok KH, Zhu Z, et al. Genomic characterization of the 2019 novel human-pathogenic coronavirus isolated from a patient with atypical pneumonia after visiting Wuhan. Emerg Microbes Infect. 2020;9(1):221236. doi: $10.1080 / 22221751.2020 .1719902$

20. Chen N, Zhou M, Dong X, et al. Epidemiological and clinical characteristics of 99 cases of 2019 novel coronavirus pneumonia in Wuhan, China: a descriptive study. Lancet. 2020;395(10223):507-513. doi: 10.1016/S0140-6736(20)30211-7

21. Chen T, Wu D, Chen $\mathrm{H}$, et al. Clinical characteristics of 113 deceased patients with coronavirus disease 2019: Retrospective study. BMJ. 2020;368. doi: 10.1136/bmj. m1091

22. Hui DS, I Azhar E, Madani TA, et al. The continuing 2019nCoV epidemic threat of novel coronaviruses to global health - The latest 2019 novel coronavirus outbreak in Wuhan, China. Int J Infect Dis. 2020;91:264-266. doi: 10.1016/j.ijid.2020.01.009

23. Zhou L, Liu HG. [Early detection and disease assessment of patients with novel coronavirus pneumonia]. Zhonghua Jie He He Hu Xi Za Zhi. 2020;43(3):167-170. doi: 10.3760/cma.j.issn.1001-0939.2020.03.003

24. Sun P, Qie S, Liu Z, Ren J, Li K, Xi J. Clinical characteristics of hospitalized patients with SARS-CoV-2 infection: A single arm meta-analysis. J Med Virol. 2020;92(6):612617. doi: $10.1002 / j m v .25735$

25. Cothran TP, Kellman S, Singh S, et al. A brewing storm: The neuropsychological sequelae of hyperinflammation due to COVID-19. Brain Behav Immun. 2020. doi: 10.1016/j.bbi.2020.06.008

26. Kotfis K, Williams Roberson S, Wilson JE, Dabrowski W, Pun BT, Ely EW. COVID-19: ICU delirium management during SARS-CoV-2 pandemic. Crit Care. 2020;24(1):176. doi: 10.1186/s13054-020-02882-x

27. Ollarves-Carrero MF, Rodriguez-Morales AG, BonillaAldana DK, Rodriguez-Morales AJ. Anosmia in a healthcare worker with COVID-19 in Madrid, Spain. Travel Med Infect Dis. 2020;35:101666-101666. doi: 10.1016/j.tmaid.2020.101666

28. Jones VG, Mills M, Suarez D, et al. COVID-19 and Kawasaki Disease: Novel Virus and Novel Case. Hosp Pediatr. 2020;10(6). doi: 10.1542/hpeds.2020-0123

29. Wang L, Shi Y, Xiao T, et al. Chinese expert consensus on the perinatal and neonatal management for the prevention and control of the 2019 novel coronavirus infection (First edition). Ann Trans/ Med. 2020;8(3):4747. doi: $10.21037 /$ atm. 2020.02 .20

30. Liang L-L, Tseng C-H, Ho HJ, Wu C-Y. Covid-19 mortality is negatively associated with test number and government effectiveness. Sci Rep. 2020;10(1):12567. doi: 10.1038/s41598-020-68862-x

31. Zhou F, Yu T, Du R, et al. Clinical course and risk factors for mortality of adult inpatients with COVID-19 in
Wuhan, China: a retrospective cohort study. Lancet. 2020;395(10229):1054-1062. doi: 10.1016/S01406736(20)30566-3

32. Chu DK, AkI EA, Duda S, Solo K, Yaacoub S, Schunemann HJ. Physical distancing, face masks, and eye protection to prevent person-to-person transmission of SARSCoV-2 and COVID-19: a systematic review and metaanalysis. www.thelancet.com. 2020;395. doi: 10.1016/ S0140-6736(20)31142-9

33. Strategies for Optimizing the Supply of N95 Respirators: COVID-19 | CDC. https://www.cdc.gov/ coronavirus/2019-ncov/hcp/respirators-strategy/ index.html. Accessed July 27, 2020.

34. Specialized respirators are key to stopping spread of coronavirus to medical staff | Live Science. https://www.livescience.com/respirators-preventcoronavirus-infection-study.html. Accessed July 27, 2020.

35. N95 Respirators, Surgical Masks, and Face Masks FDA. https://www.fda.gov/medical-devices/personalprotective-equipment-infection-control/n95respirators-surgical-masks-and-face-masks. Accessed July 27, 2020.

36. Lauer SA, Grantz KH, Bi Q, et al. The incubation period of coronavirus disease 2019 (CoVID-19) from publicly reported confirmed cases: Estimation and application. Ann Intern Med. 2020;172(9):577-582. doi: 10.7326/ M20-0504

37. Interim U.S. Guidance for Risk Assessment and Work Restrictions for Healthcare Personnel with Potential Exposure to COVID-19 CDC. https://www.cdc.gov/ coronavirus/2019-ncov/hcp/guidance-risk-assesmenthcp.html. Accessed July 27, 2020.

38. First coronavirus death in California linked to Princess Cruise ship. The Seattle Times. https://www. seattletimes.com/nation-world/first-coronavirusdeath-in-california-linked-to-princess-cruise-ship/. Accessed July 27, 2020.

39. Live coronavirus updates: Grand Princess cruise ship heads back to sea after restocking supplies in San Francisco - ABC30 Fresno. https://abc30.com/ coronavirus-princess-cruise-san-francisco-grand-shipdocking/5996768/. Accessed July 27, 2020.

40. Wilder-Smith A, Chiew CJ, Lee VJ. Can we contain the COVID-19 outbreak with the same measures as for SARS? Lancet Infect Dis. 2020;20(5):e102-e107. doi: 10.1016/S1473-3099(20)30129-8

41. Cetron $M$, Simone P. Battling $21^{\text {st }}$-century scourges with a $14^{\text {th }}$-century toolbox. Emerg Infect Dis. 2004;10(11):2053-2054. doi: 10.3201/ eid1011.040797_12

42. Ahmad T, Haroon, Dhama K, et al. Biosafety and biosecurity approaches to restrain/contain and counter SARS-CoV-2/ COVID-19 pandemic: A rapidreview. Turkish J Biol. 2020;44(Special issue 1):132145. doi: 10.3906/biy-2005-63

43. Morawska L, Cao J. Airborne transmission of SARSCoV-2: The world should face the reality. Environ Int. 2020;139. doi: 10.1016/j.envint.2020.105730

44. Zhang $R$, Li $Y$, Zhang AL, Wang $Y$, Molina MJ. Identifying airborne transmission as the dominant 
route for the spread of COVID-19. Proc Natl Acad Sci. 2020;117(26):202009637. doi: 10.1073/ pnas. 2009637117

45. Setti L, Passarini F, De Gennaro G, et al. Airborne transmission route of covid-19: Why 2 meters $/ 6$ feet of inter-personal distance could not be enough. Int $J$ Environ Res Public Health. 2020;17(8). doi: 10.3390/ ijerph17082932

46. Bonato G, Dioscoridi L, Mutignani M. Faecaloral transmission of SARS-COV-2: practical implications. Gastroenterology. 2020. doi: 10.1053/j. gastro.2020.03.066

47. Hart OE, Halden RU. Computational analysis of SARS-CoV-2/COVID-19 surveillance by wastewaterbased epidemiology locally and globally: Feasibility, economy, opportunities and challenges. Sci Total Environ. 2020;730:138875. doi: 10.1016/j. scitotenv.2020.138875

48. Lodder W, de Roda Husman AM. SARS-CoV-2 in wastewater: potential health risk, but also data source. Lancet Gastroenterol Hepatol. 2020;5(6):533-534. doi: 10.1016/S2468-1253(20)30087-X

49. Quilliam RS, Weidmann M, Moresco V, Purshouse $H$, O'Hara Z, Oliver DM. COVID-19: The environmental implications of shedding SARS-CoV-2 in human faeces. Environ Int. 2020;140:105790. doi: 10.1016/j. envint.2020.105790

50. Orive G, Lertxundi U, Barcelo D. Early SARS-CoV-2 outbreak detection by sewage-based epidemiology. Sci Total Environ. 2020;732:139298. doi: 10.1016/j. scitotenv.2020.139298

51. Lotfi M, Hamblin MR, Rezaei N. COVID-19: Transmission, prevention, and potential therapeutic opportunities. Clin Chim Acta. 2020;508:254-266. doi: 10.1016/j. cca.2020.05.044

52. Begley S. Which Groups Are Most at Risk from the Coronavirus? Sci Am J. 2020. https://www. scientificamerican.com/article/which-groups-aremost-at-risk-from-the-coronavirus/

53. Here's who's most at risk from the novel coronavirus - The Verge. https://www.theverge. com/2020/3/11/21173157/coronavirus-healtheffects-age-covid-risk-diabetes-hypertension-diseaseisolation. Accessed July 27, 2020.

54. Martins-Filho PR, Tanajura DM, Santos HP, Santos VS. COVID-19 during pregnancy: Potential risk for neurodevelopmental disorders in neonates? Eur J Obstet Gynecol Reprod Biol. 2020;250:255. doi: 10.1016/j.ejogrb.2020.05.015

55. Qiancheng X, Jian S, Lingling P, et al. Coronavirus disease 2019 in pregnancy. Int J Infect Dis. 2020;95:376-383. doi: 10.1016/j.ijid.2020.04.065

56. De Luca CD, Esposito E, Cristiani L, et al. Covid-19 in children: A brief overview after three months experience. Paediatr Respir Rev. 2020. doi: 10.1016/j. prrv.2020.05.006

57. Information for Healthcare Professionals Coronavirus (COVID-19) Infection in Pregnancy. Version 11. Royal college of Pediatrics and Child Health, Royal college of Anesthetists; 2020.

58. Lacroix I, Benevent J, Damase-Michel C. Chloroquine and hydroxychloroquine during pregnancy: What do we know? Therapies. 2020. doi: 10.1016/j. therap.2020.05.004

59. Coronavirus: The Case for Canceling Everything - The Atlantic. https://www.theatlantic.com/ ideas/archive/2020/03/coronavirus-canceleverything/607675/. Accessed July 27, 2020.

60. Tiwari R, Dhama K, Sharun K, et al. COVID-19: animals, veterinary and zoonotic links. Vet Q. 2020;40(1):169182. doi: $10.1080 / 01652176.2020 .1766725$

61. Dodds J. Mapsci-JIA-1(2)-010 / Case Report Citation: Dodds WJ. Coronavirus SARS-CoV-2 (COVID-19) and Companion Animal Pets. Vol 1.; 2020.

62. Mallapaty S. Coronavirus can infect cats - dogs, not so much. Nature. April 2020. doi: 10.1038/d41586-02000984-8

63. Shi J, Wen Z, Zhong G, et al. Susceptibility of ferrets, cats, dogs, and other domesticated animals to SARScoronavirus 2. Science. 2020;368(6494):1016-1020. doi: 10.1126/science.abb7015

64. Oreshkova N, Molenaar RJ, Vreman S, et al. SARSCoV-2 infection in farmed minks, the Netherlands. Eurosurveillance. 2020;25(23):2001005. doi: 10.2807/1560-7917.ES.2020.25.23.2001005

65. Tiwari R, Latheef SK, Ahmed I, et al. Herbal immunomodulators, a remedial panacea for the designing and developing effective drugs and medicines: Current scenario and future prospects. Curr Drug Metab. 2018;19(3). doi: 10.2174/1389200 219666180129125436

66. Dhama K, Verma AK, Tiwari R, et al. A perspective on applications of geographical information system (GIS); an advanced tracking tool for disease surveillance and monitoring in veterinary epidemiology. Adv Anim Vet Sci. 2020;1(1):14-24. https://www.researchgate. net/publication/259870643_A_perspective_on_ applications_of_geographical_information_system_ GIS_an_advanced_tracking_tool_for_disease surveillance_and_monitoring_in_veterinary_ epidemiology. Accessed July 27, 2020.

67. Bonilla-Aldana DK, Dhama K, Rodriguez-Morales AJ. Revisiting the one health approach in the context of COVID-19: A look into the ecology of this emerging disease. Adv Anim Vet Sci. 2020;8(3). doi: 10.17582/ journal.aavs/2020/8.3.234.237

68. Leroy EM, Ar Gouilh M, Brugere-Picoux J. The risk of SARS-CoV-2 transmission to pets and other wild and domestic animals strongly mandates a one-health strategy to control the COVID-19 pandemic. One Heal. 2020. doi: 10.1016/j.onehlt.2020.100133

69. Ciotti M, Ciccozzi M, Terrinoni A, Jiang WC, Wang C Bin, Bernardini S. The COVID-19 pandemic. Crit Rev Clin Lab Sci. 2020:1-24. doi: 10.1080/10408363.2020.1783198

70. Dhama K, Sharun K, Tiwari R, et al. Corona virus covid 19. Prepints. 2020;(March). doi: 10.20944/ preprints202003.0001.v1

71. Keni R, Alexander A, Nayak PG, Mudgal J, Nandakumar K. COVID-19: Emergence, Spread, Possible Treatments, and Global Burden. Front Public Heal. 2020;8:216. doi: 10.3389/fpubh.2020.00216

72. Malik YS, Kumar N, Sircar S, et al. Coronavirus Disease 
Pandemic (COVID-19): Challenges and a Global Perspective. Pathogens. 2020;9(7):519. doi: 10.3390/ pathogens9070519

73. Prompetchara E, Ketloy C, Palaga T. Immune responses in COVID-19 and potential vaccines: Lessons learned from SARS and MERS epidemic. Asian Pacific J Allergy Immunol. 2020;38(1):1-9. doi: 10.12932/AP-2002200772

74. Iqbal Yatoo M, Hamid Z, Parray OR, et al. COVID-19 - Recent advancements in identifying novel vaccine candidates and current status of upcoming SARS-CoV-2 vaccines. Hum Vaccin Immunother. 2020:1-14. doi: 10.1080/21645515.2020.1788310

75. Abbott TR, Dhamdhere G, Liu Y, et al. Development of CRISPR as an Antiviral Strategy to Combat SARS-CoV-2 and Influenza. Cell. 2020;181(4):865-876.e12. doi: 10.1016/j.cell.2020.04.020

76. Ahuja AS, Reddy VP, Marques O. Artificial intelligence and COVID-19: A multidisciplinary approach. Integr Med Res. 2020;9(3):100434. doi: 10.1016/j. imr.2020.100434

77. Omolo CA, Soni N, Fasiku VO, Mackraj I, Govender T. Update on therapeutic approaches and emerging therapies for SARS-CoV-2 virus. Eur J Pharmacol. 2020:173348. doi: 10.1016/j.ejphar.2020.173348

78. Casadevall A, Pirofski LA. The convalescent sera option for containing COVID-19. J Clin Invest. 2020;130(4):1545-1548. doi: 10.1172/JCl138003

79. Venkat Kumar G, Jeyanthi V, Ramakrishnan S. A short review on antibody therapy for COVID-19. New Microbes New Infect. 2020;35:100682. doi: 10.1016/j. nmni.2020.100682

80. Market $M$, Angka L, Martel AB, et al. Flattening the COVID-19 Curve With Natural Killer Cell Based Immunotherapies. Front Immunol. 2020;11:1512. doi: 10.3389/fimmu.2020.01512

81. Shanmugaraj B, Siriwattananon K, Wangkanont K, Phoolcharoen W. Perspectives on monoclonal antibody therapy as potential therapeutic intervention for Coronavirus disease-19 (COVID-19). Asian Pacific J Allergy Immunol. 2020;38(1):10-18. doi: 10.12932/ AP-200220-0773

82. Keam S, Megawati D, Patel SK, Tiwari R, Dhama K, Harapan H. Immunopathology and immunotherapeutic strategies in severe acute respiratory syndrome coronavirus 2 infection. Rev Med Virol. 2020. doi: 10.1002/rmv.2123

83. Vellingiri B, Jayaramayya $\mathrm{K}$, lyer $\mathrm{M}$, et al. COVID-19: A promising cure for the global panic. Sci Total Environ. 2020;725:138277. doi: $10.1016 / \mathrm{j}$. scitotenv.2020.138277

84. Rastogi S, Pandey DN, Singh RH. COVID-19 pandemic: A pragmatic plan for ayurveda intervention. J Ayurveda Integr Med. 2020. doi: 10.1016/j.jaim.2020.04.002

85. Prasad A, Muthamilarasan M, Prasad M. Synergistic antiviral effects against SARS-CoV-2 by plant-based molecules. Plant Cell Rep. 2020;1:3. ddoi: 10.1007/ s00299-020-02560-w

86. Morais AHA, Passos TS, Maciel BLL, da Silva-Maia JK. Can probiotics and diet promote beneficial immune modulation and purine control in coronavirus infection? Nutrients. 2020;12(6):1-18. doi: 10.3390/ nu12061737

87. Jahan I, Onay A. Potentials of plant-based substance to inhabit and probable cure for the covid-19. Turkish J Biol. 2020;44(Special issue 1):228-241. doi: 10.3906/ biy-2005-114

88. Infusino $\mathrm{F}$, Marazzato $\mathrm{M}$, Mancone $\mathrm{M}$, et al. Diet supplementation, probiotics, and nutraceuticals in SARS-CoV-2 infection: A scoping review. Nutrients. 2020;12(6):1-21. doi: 10.3390/nu12061718

89. Galanakis $\mathrm{CM}$. The food systems in the era of the coronavirus (CoVID-19) pandemic crisis. Foods. 2020;9(4). doi: 10.3390/foods9040523

90. Dhama K, Karthik K, Khandia R, et al. Medicinal and Therapeutic Potential of Herbs and Plant Metabolites / Extracts Countering Viral Pathogens - Current Knowledge and Future Prospects. Curr Drug Metab. 2018;19(3). doi: 10.2174/138920021966618012914 5252

91. Chen L, Hu C, Hood M, et al. A novel combination of vitamin c, curcumin and glycyrrhizic acid potentially regulates immune and inflammatory response associated with coronavirus infections: A perspective from system biology analysis. Nutrients. 2020;12(4). doi: 10.3390/nu12041193

92. Gangal N, Nagle V, Pawa Y. Reconsidering Traditional Medicinal Plants to Combat COVID-19 AIJR Preprints. AIJR. 2020. https://preprints.aijr.org/index.php/ap/ preprint/view/34. Accessed July 27, 2020.

93. Dhama K, Saminathan M, Jacob SS, et al. Effect of immunomodulation and immunomodulatory agents on health with some bioactive principles, modes of action and potent biomedical applications. Int J Pharmacol. 2015;11(4):253-290. doi: 10.3923/ ijp.2015.253.290

94. Zhong J, Tang J, Ye C, Dong L. The immunology of COVID-19: is immune modulation an option for treatment? Lancet Rheumatol. 2020;2(7):428-464. doi: 10.1016/S2665-9913(20)30120-X

95. Tiwari R, Latheef SK, Ahmed I, et al. Herbal Immunomodulators - A Remedial Panacea for Designing and Developing Effective Drugs and Medicines: Current Scenario and Future Prospects. Curr Drug Metab. 2018;19(3):264-301. doi: 10.2174/ 1389200219666180129125436

96. Vellingiri B, Jayaramayya $K$, Iyer $M$, et al. COVID-19: A promising cure for the global panic. Sci Total Environ. 2020;725:138277-138277. doi: 10.1016/j. scitotenv.2020.138277

97. Gupta A. Is Immuno-modulation the Key to COVID-19 Pandemic? Indian J Orthop. 2020;54(3):394-397. doi: 10.1007/s43465-020-00121-7

98. Riva L, Yuan S, Yin X, et al. Discovery of SARS-CoV-2 antiviral drugs through large-scale compound repurposing. Nature. July 2020:1-11. doi: 10.1038/ s41586-020-2577-1

99. Jayaweera M, Perera H, Gunawardana B, Manatunge J. Transmission of COVID-19 virus by droplets and aerosols: A critical review on the unresolved dichotomy. Environ Res. 2020;188:109819. doi: 10.1016/j.envres.2020.109819 
100. Guner R, Hasanoglu L, Aktas F. Covid-19: Prevention and control measures in community. Turkish J Med Sci. 2020;50(SI-1):571-577. doi: 10.3906/sag-2004-146

101. Tang A, Tong Z, Wang H, et al. Detection of Novel Coronavirus by RT-PCR in Stool Specimen from Asymptomatic Child, China. Emerg Infect Dis.
2020;26(6):1337-1339. doi: 10.3201/eid2606.200301 102. Dhama K, Patel SK, Pathak $M$, et al. An update on SARS-CoV-2/COVID-19 with particular reference to its clinical pathology, pathogenesis, immunopathology and mitigation strategies. Travel Med Infect Dis. 2020. doi: 10.1016/j.tmaid.2020.101755 